\title{
Exercise Improves Behavioral, Neurocognitive, and Scholastic Performance in Children with Attention-Deficit/Hyperactivity Disorder
}

\author{
Matthew B. Pontifex, $\mathrm{PhD}^{1}$, Brian J. Saliba, BS ${ }^{1}$, Lauren B. Raine, $\mathrm{BS}^{1}$, Daniel L. Picchietti, $\mathrm{MD}^{1,2}$, and Charles H. Hillman, $\mathrm{PhD}^{1}$ \\ Objective To examine the effect of a single bout of moderate-intensity aerobic exercise on preadolescent children \\ with attention-deficit/hyperactivity disorder (ADHD) using objective measures of attention, brain neurophysiology, \\ and academic performance.
}

Study design Using a within-participants design, task performance and event-related brain potentials were assessed while participants performed an attentional-control task following a bout of exercise or seated reading during 2 separate, counterbalanced sessions.

Results Following a single 20-minute bout of exercise, both children with ADHD and healthy match control children exhibited greater response accuracy and stimulus-related processing, with the children with ADHD also exhibiting selective enhancements in regulatory processes, compared with after a similar duration of seated reading. In addition, greater performance in the areas of reading and arithmetic were observed following exercise in both groups.

Conclusion These findings indicate that single bouts of moderately intense aerobic exercise may have positive implications for aspects of neurocognitive function and inhibitory control in children with ADHD. (J Pediatr 2013;162:543-51).

ttention-deficit/hyperactivity disorder (ADHD) affects more than 2.5 million school-aged children in the US. ${ }^{1-3}$ ADHD is characterized by developmentally inappropriate levels of inattention, overactivity, distractibility, and impulsiveness, which manifest during childhood. ${ }^{1,4,5}$ Research suggests that failures in inhibitory control, as well as the neural processes subserving inhibitory control, may represent the core cognitive deficit underlying the manifestation of ADHD. ${ }^{6}$ Specifically, a growing body of research has suggested that ADHD-related deficits in inhibitory control are associated with failures in the cascade of processes underlying the stimulus-response relationship, including reductions in the allocation of attentional resources, delays in the speed at which stimuli are processed, and failures to appropriately implement action monitoring processes as assessed using neuroelectric measures. ${ }^{7-16}$ Although pharmacologic treatments have largely proven effective in managing ADHD symptoms, ${ }^{17}$ potential adverse effects, high costs, and incomplete responses argue for other treatments for children with ADHD. ${ }^{18,19}$

Reports from parents, teachers, and scholars have suggested that one such treatment option may be single bouts of shortduration, moderate-intensity aerobic exercise. ${ }^{20-22}$ Despite some recent findings by Medina et al ${ }^{23}$ suggesting that single bouts of exercise may facilitate reaction time (RT)-based measures of attentional vigilance, there is a paucity of empirically sound evidence in children with ADHD to support such claims. The vast majority of support for these assertions is drawn from previous research in healthy children, suggesting that participation in a single bout of structured physical activities lasting at least 20 minutes is beneficial for various cognitive functions, including aspects of concentration, ${ }^{24-26}$ brief tests of reading and mathematics achievement, ${ }^{27,28}$ and inhibitory control. ${ }^{28}$ The effects of single bouts of exercise also appear to mirror the neurocognitive deficits associated with ADHD, such that a single bout of moderate-intensity aerobic exercise serves to increase the allocation of attentional resources, and facilitates stimulus classification and processing speed, with a disproportionately larger effect for task conditions with the greatest inhibitory control demands. ${ }^{29-32}$ Accordingly, given the striking similarity between the aspects of cognition that are influenced by acute exercise and those that exhibit ADHD-related deficits, the purpose of this study was to examine the effect of a single bout of aerobic exercise on the modulation of inhibitory control deficits in children with ADHD using objective measures of behavioral inhibition, neurocognitive function, and scholastic performance. It was hypothesized that children with ADHD would experience similar benefits from acute exercise as those experienced by children without $\mathrm{ADHD},{ }^{28}$ with greater response execution, attentional allocation, and scholastic achievement being observed after a bout of moderate-intensity exercise.

\footnotetext{
ADHD Attention-deficit/hyperactivity disorder

ERN Error-related negativity

ERP Event-related brain potential

RT Reaction time

WRAT3 Wide Range Achievement Test, 3rd edition
}

From the ${ }^{1}$ Department of Kinesiology and Community Health, University of Illinois at Urbana-Champaign; and ${ }^{2}$ Department of Pediatrics, Carle Foundation Hospital, Urbana, IL

Supported by the National Institute of Child Health and Human Development (NICHD; R01 HD055352 to C.H.) and the NICHD Developmental Psychobiology and Neurobiology Training Grant at the University of Illinois (2 T32 HD007333 to M.P.). The authors declare no conflicts of interest.

0022-3476/\$ - see front matter. Copyright $\odot 2013$ Mosby Inc. All rights reserved. http://dx.doi.org/10.1016/j.jpeds.2012.08.036 


\section{Methods}

The ADHD group comprised 20 children ( 6 females) aged 8-10 years recruited from the east-central Illinois area based on suspected or diagnosed ADHD free of any comorbid conditions (Table I). The term "suspected ADHD" refers to children whose parents, school staff, or primary care provider expressed suspicion of ADHD but for whom no diagnostic assessment had been sought from a developmental specialist. ${ }^{33}$ Clinical status was verified through the ADHD supplement of the Kiddie Schedule for Affective Disorders and Schizophrenia, Present and Lifetime Version semistructured diagnostic interview using Diagnostic and Statistical Manual of Mental Disorders, Fourth Edition, Text Revision criteria for any subtype of ADHD, including evidence for impairment in 2 or more settings and onset of symptoms before age 7 years. ${ }^{1}$ Children with ADHD were screened to ensure that they currently exhibited ongoing ADHD symptoms using the ADHD Rating Scale IV. ${ }^{34}$ Healthy match control children were yoked by sex, age, pubertal status, and socioeconomic status, with no significant differences observed between the groups $[t(38) \leq 1.6$; $P \geq .12$ for all]. All participants had normal or corrected-tonormal vision and were free of any central nervous system active drug therapy for at least 1 month before testing. All participants were screened for comorbid conditions, including autism spectrum disorders, using the Social Communication Questionnaire, ${ }^{35}$ and for anxiety, conduct, somatic, and affective disorders (including depressive and bipolar disorders) using the Diagnostic and Statistical Manual-oriented scores of the Child Behavioral Checklist. ${ }^{36}$ All participants provided written assent, and their legal guardians provided written informed consent in accordance with the Institutional Review Boards of the University of Illinois at Urbana-Champaign and Carle Foundation Hospital.

\section{Inhibitory Control Task}

Participants completed a modified version of the Eriksen flanker task $\mathrm{k}^{9,37}$ to assess inhibitory aspects of cognitive control. This paradigm is conceptually simplistic in that it requires the discrimination of a centrally presented target stimulus amid lateral flanking stimuli. In this task, participants were required to make a left-hand thumb press on a Neuroscan STIM system switch response pad (Compumedics, Charlotte, North Carolina) when the target stimulus pointed left and a right-hand thumb press when the target stimulus pointed right. Thus, participants were instructed to respond as accurately as possible to the direction of a centrally presented target fish amid either congruous (target facing the same direction) or incongruous (target facing the opposite direction) flanking goldfish. The task also manipulated stimulus-response compatibility to vary cognitive control requirements by instructing participants first to complete a compatible condition (described above), and then complete an incompatible condition in which they were instructed to respond in the direction opposite that of the centrally presented target arrow (ie, when the target fish pointed left, the correct response was to the right, and vice versa ${ }^{38}$ ). For each compatibility condition, 2 blocks of 100 trials were presented with equiprobable congruency and directionality. The stimuli were 3-cm-tall yellow fish, which were presented focally for $200 \mathrm{~ms}$ on a blue background, with a fixed interstimulus interval of $1700 \mathrm{~ms}$. This task allows for the assessment of a number of variables, including median RT (to better represent the central response tendency of children with $\mathrm{ADHD}^{39-41}$ ) and response accuracy. Furthermore, the trial-by-trial nature of the task allows for assessment of median RT for correct trials immediately following an error $(n+1$, termed posterror median RT), which provides a behavioral indicator of the increased recruitment and implementation of top-down control, ${ }^{42,43}$ as well as for correct trials following a match correct trial (a subset of correct trials matched to specific error trials based on RT). ${ }^{44}$

Table I. Participant demographic and clinical characteristics ( \pm 1 SE)

\begin{tabular}{|c|c|c|c|c|c|}
\hline \multirow[b]{2}{*}{ Measure } & \multicolumn{3}{|c|}{ ADHD subtype } & \multirow{2}{*}{$\begin{array}{l}\text { Healthy match } \\
\text { control }\end{array}$} & \multirow[b]{2}{*}{$P$ value ${ }^{x}$} \\
\hline & ADHD-C & ADHD-I & ADHD-H & & \\
\hline Number & 6 (2 females) & 11 (3 females) & 3 (1 female) & 20 (6 females) & \\
\hline Age, years & $9.3 \pm 0.3$ & $9.5 \pm 0.3$ & $9.6 \pm 0.9$ & $9.8 \pm 0.1$ & .13 \\
\hline Tanner stage & $1.5 \pm 0.1$ & $1.5 \pm 0.2$ & $1.0 \pm 0.0$ & $1.4 \pm 0.1$ & .86 \\
\hline Kaufman Brief Intelligence Test composite (IQ) & $111.7 \pm 4.6$ & $110.2 \pm 4.0$ & $121.3 \pm 2.7$ & $118.7 \pm 2.9$ & .12 \\
\hline Socioeconomic status & $2.5 \pm 0.3$ & $2.0 \pm 0.3$ & $3.0 \pm 0.0$ & $2.3 \pm 0.2$ & .99 \\
\hline Body mass index, $\mathrm{kg} / \mathrm{m}^{2}$ & $16.7 \pm 0.6$ & $18.5 \pm 0.9$ & $14.1 \pm 0.3$ & $20.0 \pm 1.2$ & .06 \\
\hline K-SADS-PL inattentive symptoms & $7.3 \pm 0.3^{\dagger}$ & $7.0 \pm 0.3^{\dagger}$ & $3.7 \pm 1.3$ & - & - \\
\hline K-SADS-PL impulsive/hyperactive symptoms & $6.5 \pm 0.2^{\dagger}$ & $3.3 \pm 0.4$ & $8.0 \pm 1.0^{\dagger}$ & - & - \\
\hline ADHD-IV Composite percentile & $98.2 \pm 1.3^{\dagger}$ & $98.2 \pm 0.7^{\dagger}$ & $90.0 \pm 5.5^{\dagger}$ & $31.3 \pm 4.2$ & $<.001$ \\
\hline ADHD-IV Inattentive percentile & $92.7 \pm 4.1^{\dagger}$ & $92.0 \pm 2.2^{\dagger}$ & $62.3 \pm 12.3$ & $36.8 \pm 5.6$ & $<.001$ \\
\hline ADHD-IV Impulsive/Hyperactive percentile & $94.5 \pm 2.1^{\dagger}$ & $80.5 \pm 6.1$ & $91.3 \pm 0.9^{\dagger}$ & $37.5 \pm 5.1$ & $<.001$ \\
\hline DBRS Distractible subscale $t$ score & $66.2 \pm 6.5^{\dagger}$ & $64.7 \pm 3.5^{\dagger}$ & $49.3 \pm 2.9$ & $44.8 \pm 1.2$ & $<.001$ \\
\hline DBRS Impulsive-Hyperactive subscale $t$ score & $65.5 \pm 4.5^{\dagger}$ & $59.8 \pm 3.2$ & $56.0 \pm 6.4$ & $44.9 \pm 1.3$ & $<.001$ \\
\hline DBRS ODD subscale $t$ score & $57.0 \pm 3.5$ & $51.0 \pm 3.3$ & $47.7 \pm 4.3$ & $43.7 \pm 1.0$ & .001 \\
\hline Autism spectrum disorder score & $7.0 \pm 1.1$ & $4.6 \pm 1.0$ & $7.3 \pm 0.9$ & $3.5 \pm 0.8$ & .04 \\
\hline
\end{tabular}

$D B R S$, Disruptive Behavior Rating Scale; K-SADS-PL, Kiddie Schedule for Affective Disorders and Schizophrenia-Present and Lifetime Version; ODD, oppositional defiance disorder ADHD subtype was based on K-SADS-PL diagnostic interview classification.

*Analysis was conducted between the participants with ADHD and the healthy match control group.

†Denotes clinically significant values for each severity scale. Percentiles $\geq 90$ on the ADHD-IV rating scale indicate high likelihood for the presence of ADHD. $t s c o r e s<60$ on the DBRS are considered normal behavioral ratings. Children with $\mathrm{ADHD}$ scoring high on the ODD subscale of the DBRS were retained, given the high comorbidity between $\mathrm{ADHD}$ and $\mathrm{ODD}$. ${ }^{83}$ An autism spectrum disorder score $<15$ indicates the absence of autism spectrum disorders. 


\section{Neuroelectric Assessment}

A Neuroscan Synamps 2 amplifier (Compumedics) was used to acquire event-related brain potentials (ERPs) in response to the modified flanker task using established protocols for data acquisition and processing. ${ }^{38}$ ERPs refer to a class of electroencephalographic activity that occurs in response to, or in preparation for, an event. ${ }^{45}$ Accordingly, the evaluation of ERPs provides additional insight into the subset of processes that occur between stimulus encoding and response production. Of interest to the present investigation are 2 prominent ERP components, P3 (also known as P300 or P3b) and errorrelated negativity (ERN; also known as $\mathrm{Ne}$ ). $\mathrm{P} 3$ is a positivegoing deflection in the ERP waveform that occurs in response to a stimulus, with the size of the component reflecting the allocation of attentional resources toward stimulus engagement. ${ }^{46}$ The latency of $\mathrm{P} 3$, which refers to the time point corresponding to the maximum peak amplitude, is generally considered a measure of stimulus classification and processing speed. ${ }^{47}$ In this study, the P3 component was evaluated as the mean amplitude within a 50-ms interval surrounding the largest positive going peak within a 300- to 700-ms latency window. The ERN, in contrast, occurs in response to conflicting actions, such as erroneous behavior, and is thought to reflect activation of action monitoring processes to initiate the up-regulation of top-down compensatory processes. ${ }^{48}$ The ERN component was evaluated as the mean amplitude within a 50-ms interval surrounding the largest negative going peak within a 0 - to $150-\mathrm{ms}$ window relative to the response.

\section{Academic Performance Assessment}

Participants also completed the Wide Range Achievement Test, 3rd Edition (WRAT3; Wide Range, Wilmington, Delaware) to assess performance in reading comprehension, spelling, and arithmetic. The WRAT3 is a brief ( $\sim 15$ minutes) assessment, which allows for repeated administration through the use of 2 equivalent forms. ${ }^{49}$ Performance on the WRAT3 has been found to strongly correlate with performance on the California Achievement Test Form E and the Stanford Achievement Test. ${ }^{49}$ The administration order of the WRAT3 subtests was counterbalanced across participants, yet fixed between experimental conditions.

\section{Procedure}

In this within-participants design, participants visited the laboratory on 3 separate days (mean days apart, $6.45 \pm 7.3$ days; mean time of day difference, $2.0 \pm 2.2$ hours) on which they had not previously engaged in physical education. Following provision of informed consent/assent, participants completed the Kaufman Brief Intelligence Test ${ }^{50}$ and legal guardians completed the Physical Activity Readiness Questionnaire, ${ }^{51}$ the modified Tanner Staging System questionnaire, ${ }^{52}$ the Social Communication Questionnaire, ${ }^{35}$ the Child Behavioral Checklist, ${ }^{36}$ the ADHD Rating Scale IV, ${ }^{34}$ the Disruptive Behavior Rating Scale, ${ }^{53}$ and a health history and demographics questionnaire. Participants were then counterbalanced into 2 different session orders (day 2, reading; day 3 , exercise vs day 2 , exercise; day 3 , reading), to ensure that the observed effects were not related to the specific order in which participants received the exercise and rest conditions. No significant differences in any of the dependent variables $(P \geq .08)$ were observed between session orders. The experimental conditions consisted of 20 minutes of either seated reading or aerobic exercise on a motor-driven treadmill at an intensity of $65 \%-75 \%$ of maximum heart rate $\left(\mathrm{HR}_{\text {during exercise }}=132.1 \pm 10.3 \% \mathrm{bpm}\right)$, recorded in response to a maximal exercise test using a Polar heart rate monitor (Polar WearLink+ 31; Polar Electro, Lake Success, New York), as described previously. ${ }^{28}$ On completion of the experimental conditions, participants were outfitted with an electrode cap and provided task instructions and practice trials. Once heart rate returned to within $10 \%$ of preexperimental condition levels, ${ }^{28}$ the 2 conditions of the flanker task were performed (compatible: $16.0 \pm 0.6$ minutes postexercise; incompatible: $27.4 \pm 0.8$ minutes postexercise), followed by administration of the WRAT3 (at $38.1 \pm 1.4$ minutes postexercise).

\section{Statistical Analyses}

All statistical analyses were conducted using a significance level of $P=.05$, and analyses with 3 or more withinsubjects levels used the Greenhouse-Geisser statistic with subsidiary univariate ANOVAs and Bonferroni-corrected $t$ tests for post hoc comparisons. Analyses were performed using a 2 (group: ADHD, healthy match control) $\times 2$ (session: postexercise, postreading) multivariate repeated-measures ANOVA, with additional variables nested within the primary analytical procedure based on the specific analysis. Specifically, analyses of task performance measures (median RT and response accuracy) were conducted separately in a 2 (compatibility: compatible, incompatible) $\times 2$ (congruency: congruent, incongruent) analysis, posttrial median RT was assessed in a 2 (compatibility: compatible, incompatible) $\times 2$ (accuracy: posterror, postmatch correct) analysis, and P3 ERP component was assessed separately for amplitude and latency in a 2 (compatibility: compatible, incompatible) $\times 2$ (congruency: congruent, incongruent) $\times 7$ (site: $\mathrm{Fz}, \mathrm{FCz}$, $\mathrm{Cz}, \mathrm{CPz}, \mathrm{Pz}, \mathrm{POz}, \mathrm{Oz}$ ) analysis. ${ }^{38}$ The ERN component was assessed at the $\mathrm{FCz}$ electrode site ${ }^{54-56}$ for both error and match correct trials. Finally, analysis of academic performance was conducted separately for each academic subject. Data were analyzed using PASW Statistics version 19.0 (IBM, Armonk, New York). A statistical summary table for all variables of interest is provided in Table II.

\section{Results}

\section{Task Performance}

Figure 1 illustrates the effects of group and session for response accuracy and posterror slowing. Analysis revealed that children with ADHD exhibited decreased overall response accuracy relative to the healthy match control group $(81.8 \% \pm 2.7 \%$ vs $88.8 \% \pm 1.3 \% ; P=.026$; Cohen $d=1.7$ ). However, following the single bout of exercise both groups exhibited greater response accuracy relative 


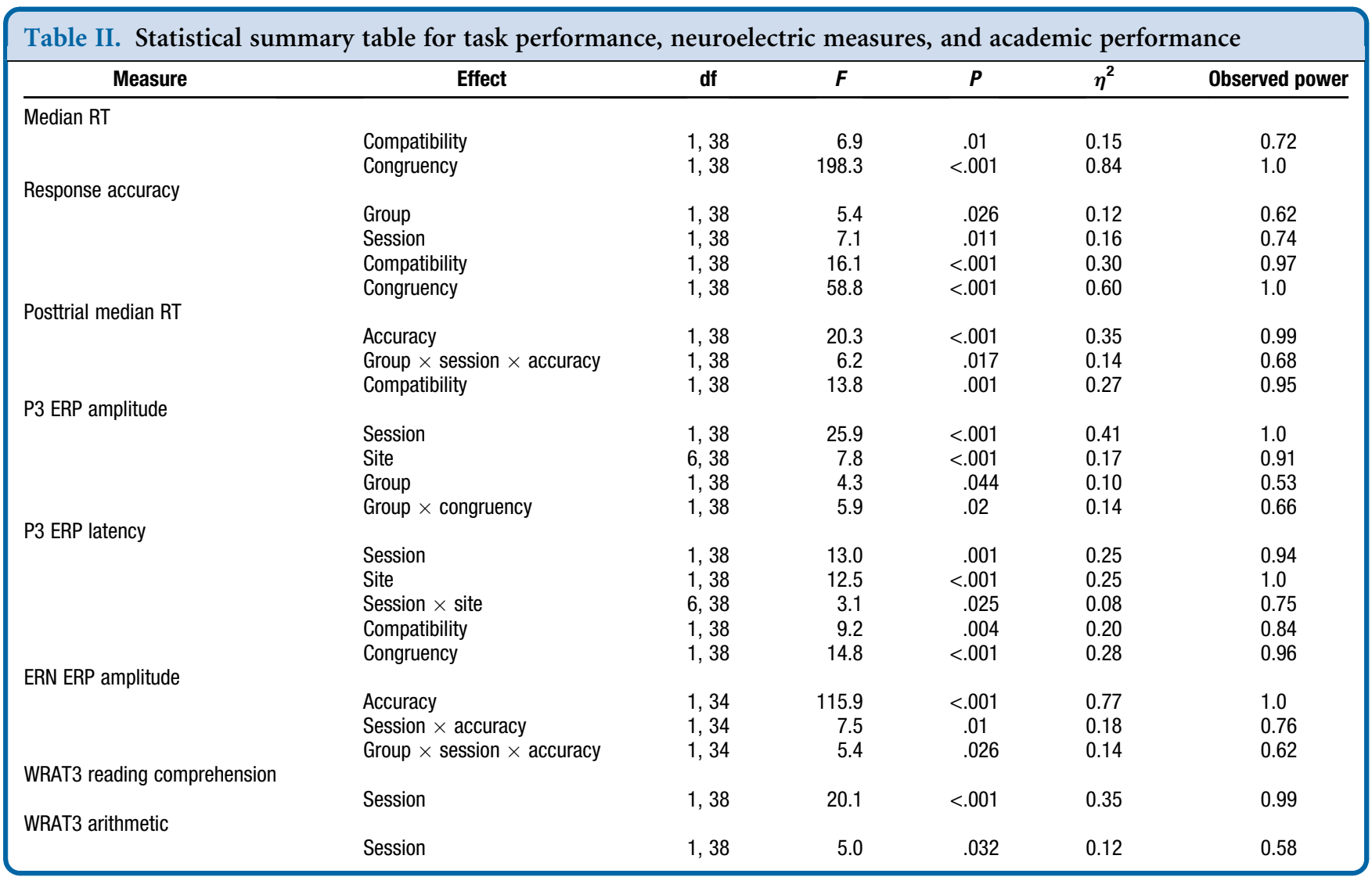

Only significant $(P<.05)$ effects are reported.

to following reading $(87.1 \% \pm 1.7 \%$ vs $83.5 \% \pm 1.8 \%$; $P=.011$; Cohen $d=0.94)$. No significant main effects or interactions involving group or session were observed for median RT $(P \geq .10)$. Analysis of median RT for trials immediately following an error revealed greater posterror slowing following the exercise condition relative to following the reading condition only for children with ADHD $[579.4 \pm 35.1 \mathrm{~ms}$ vs $500.3 \pm 32.4 \mathrm{~ms} ; t(19)=3.0$; $P=.008$; Cohen $d=1.36]$.

\section{Neuroelectric Measures}

Figure 2 illustrates the topographic distribution of P3 amplitude across the scalp and provides grand mean stimulus and response-locked ERP waveforms for each group and session. Analysis of the P3 component revealed smaller P3 amplitude in children with ADHD compared with the healthy match control group only for the incongruent trials of the flanker task [7.8 $\pm 0.6 \mu \mathrm{V}$ vs $10.1 \pm 0.6 \mu \mathrm{V} ; t(38)=2.8 ; P=.009$; Cohen $d=0.91]$. However, both children with ADHD and the healthy match control children exhibited larger P3 amplitude after exercise compared with after reading $(10.9 \pm 0.6 \mu \mathrm{V}$ vs $7.9 \pm 0.5 \mu \mathrm{V} ; P \leq .001$; Cohen $d=0.8)$. Furthermore, shorter P3 latency at the $\mathrm{FCz}, \mathrm{Cz}$, and $\mathrm{CPz}$ electrode sites was also observed after exercise compared with after reading [ $t$ (39) $\geq 3.1 ; P \leq .004$; Cohen $d=0.99$ ].

Previous research has established that a minimum of 6 error-of-commission trials are needed to obtain a stable
ERN component. ${ }^{57}$ Thus, we collapsed compatible and incompatible trials after matching error and correct trials within each compatibility, to account for potential artifacts owing to differences in response latency between correct trials and incorrect trials. ${ }^{44}$ Remaining participants with fewer than 6 errors of commission were eliminated from analysis of the ERN component ( $\mathrm{n}=4$; 2 with ADHD), leaving a total of 36 participants. No significant between-group differences in demographic variables were observed in this subset of participants $[t(34) \leq 1.8 ; P \geq .09]$. Accordingly, analysis of the ERN component (ie, the error trials in the group $\times$ session $\times$ accuracy interaction, depicted in Figure 2, C) revealed smaller ERN amplitude in the children with ADHD compared with the healthy match control group after the reading session $[-7.3 \pm 1.1 \mu \mathrm{V}$ vs $-11.2 \pm 1.1 \mu \mathrm{V} ; t(34)=2.5 ; P=.017$; Cohen $d=0.86]$. However, no between-group differences were observed after the single bout of exercise $[-10.8 \pm 1.0 \mu \mathrm{V}$ vs $-10.8 \pm 1.1$ $\mu \mathrm{V} ; t(34)=0.03 ; P=.98$; Cohen $d=0.01]$. No main effects or interactions involving group or session were observed for match correct response-locked trials (ie, the match correct trials in the group $\times$ session $\times$ accuracy interaction; $P \geq .21$; Figure 2, D).

\section{Academic Performance}

Analysis revealed that both children with ADHD and healthy match control children exhibited enhanced performance after exercise on tests of reading comprehension and arithmetic 

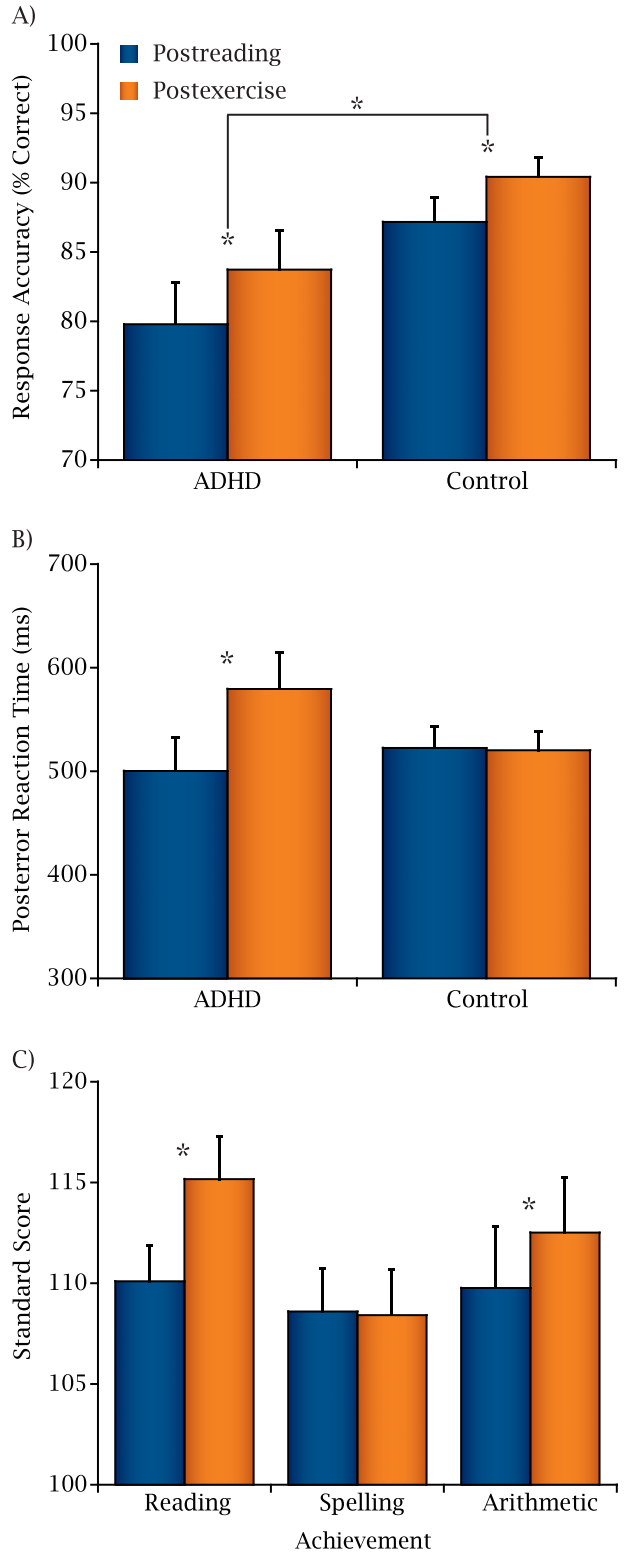

Figure 1. A, Mean ( \pm SE) response accuracy and $\mathbf{B}$, median $( \pm \mathrm{SE})$ posterror RT collapsed across compatibility and congruency conditions for each session by group. C, Mean $( \pm S E)$ standard score for each session on each of the 3 WRAT3 academic performance tests collapsed across ADHD and healthy match control groups.

compared with after the seated reading condition (reading comprehension: $115.2 \pm 2.2$ vs $110.1 \pm 1.8 ; P<.001$; Cohen $d=1.58$; arithmetic: $112.5 \pm 2.7$ vs $110.0 \pm 3.1 ; P=.03$; Cohen $d=1.25$ ) (Figure 1). No main effects or interactions involving group or session were observed for spelling $(P \geq .15)$.

\section{Discussion}

This investigation provides initial evidence suggesting that single bouts of moderate-intensity aerobic exercise may be a tool in the nonpharmaceutical treatment of children with $\mathrm{ADHD}$. That is, using objective measures to assess the effect of exercise on aspects of cognition, these findings suggest that both children with ADHD and healthy match control children exhibit overall enhancements in inhibitory control and allocation of attentional resources, coupled with selective enhancement in stimulus classification and processing speed, following a single 20-minute bout of moderate-intensity aerobic exercise. Further, acute exercise appears to have an added benefit for children with ADHD who exhibited exercise-induced facilitations in action monitoring processes (ie, ERN amplitude) and regulatory adjustments in behavior (ie, posterior slowing). These acute exercise-induced enhancements in response production and neurocognitive function also may have relevance for maximizing scholastic performance in all children, as evidenced by the exerciseinduced improvements in the areas of reading comprehension and arithmetic-subjects that have been found to depend heavily on the successful inhibition of unrelated information. ${ }^{58,59}$

Interestingly, these findings provide partial support for the hypoarousal model of ADHD, ${ }^{60}$ which suggests that cognitive and attentional deficits related to ADHD may arise as a result of underarousal of the central nervous system. However, more recent research has suggested that these deficits are not necessarily a result of deficient arousal, but instead are related to insufficient task-related activation. ${ }^{61}$ Consistent with this assertion, findings from the present investigation revealed that children with ADHD exhibited smaller P3 amplitude after reading compared with healthy match control children, only in response to the incongruent trials-replicating previous research that found ADHD-related deficits in the allocation of attentional resources for task conditions requiring the greatest amount of inhibitory control. ${ }^{9}$ Accordingly, the finding that a single bout of physical activity served to generally enhance the allocation of attentional resources toward stimulus engagement suggests that such an intervention may act to reduce the core deficit associated with ADHD proposed by the hypoarousal model of ADHD. Although pharmacologic treatments have proven largely effective in the shortterm management of $\mathrm{ADHD},{ }^{17}$ an estimated $30 \%-50 \%$ of all clinically diagnosed cases persist into adulthood. ${ }^{62}$ Given that ADHD represents one of the most prevalent childhood disorders in the US, ${ }^{1-3}$ interest has been growing in nonpharmacologic treatment strategies to reduce the potential effects of, and costs associated with, long-term psychostimulant use. ${ }^{18}$ These novel findings suggesting that single bouts of exercise may be an effective aid in the treatment of $\mathrm{ADHD}$ are both relevant and timely to this growing movement and are consistent with the aims of recently released guidelines for the treatment of ADHD. ${ }^{19}$

Furthermore, although speculative, given that changes in cognition associated with chronic physical activity participation may be accrued progressively through repeated bouts of acute exercise, such a treatment tool also may serve to create more long-term changes in inhibitory control. That is, 

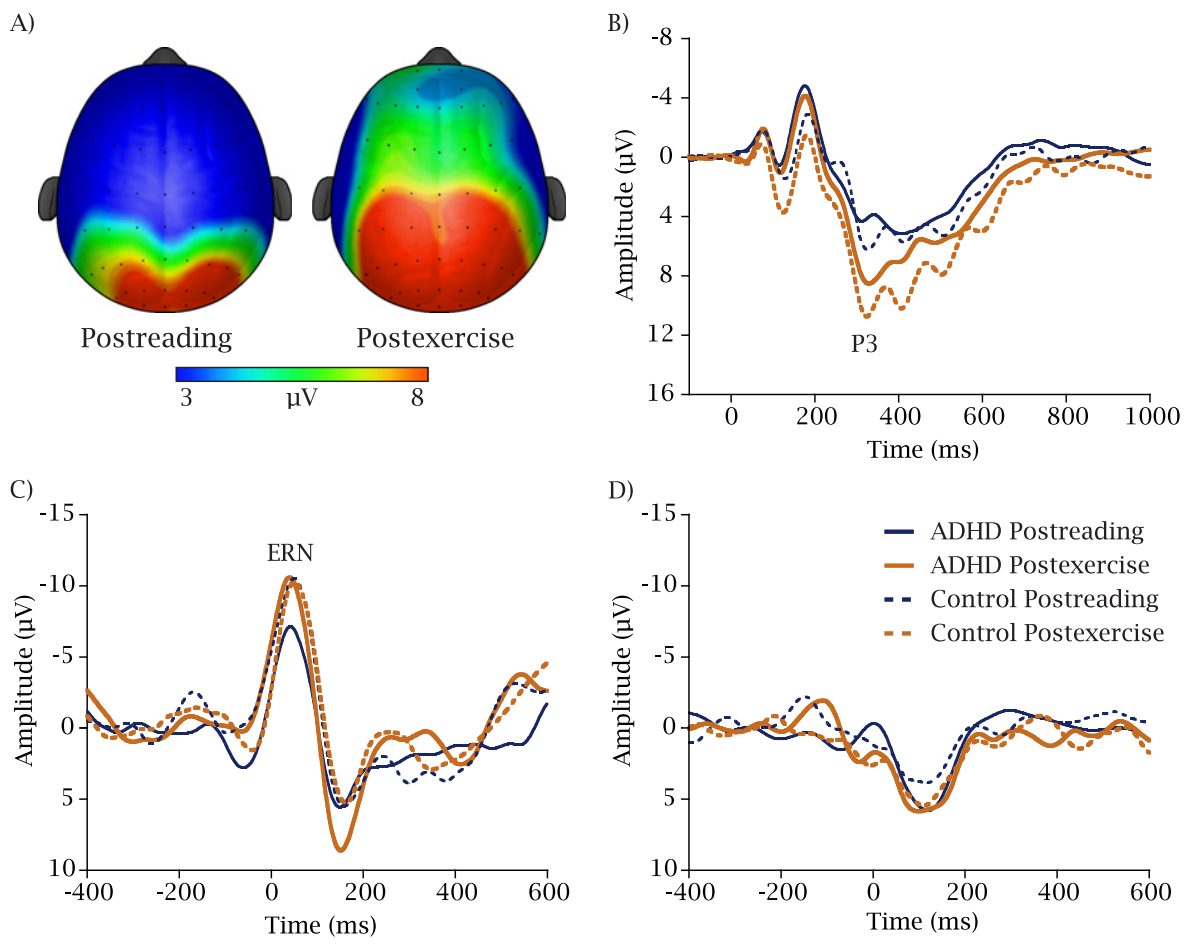

Figure 2. A, Topographic plots of $\mathrm{P} 3$ amplitude collapsed across group B, the stimulus-locked grand-average waveform from the PZ electrode site $\mathbf{C}$, the response-locked grand average waveform for error, and $\mathbf{D}$, match-correct trials for each group and session, with all graphs collapsed across compatibility and congruency conditions.

individuals with greater chronic physical activity participation and aerobic fitness levels have been found to exhibit increased tissue volume in the basal ganglia ${ }^{63}$ and hippocampus, ${ }^{64}$ as well as an enhanced ability to recruit neural resources in the frontal and parietal regions, ${ }^{65}$ in addition to functional enhancements in neural processes related to the allocation of attentional resources ${ }^{38,66}$ and greater integrity of action monitoring processes. ${ }^{38}$ Given that these neural structures and processes mirror those seen to be deficient in children with ADHD, ${ }^{8,10-13,15,16,67-76}$ over the course of repeated bouts of acute aerobic exercise, these neuronal structures and functions may be sufficiently enhanced to more enduringly alter the underlying etiology of ADHD. ${ }^{20}$ Consonant with this assertion, an initial investigation into the effects of a chronic 10-week physical activity program in 10 children with ADHD found enhanced information processing, visual search, and sustained attention relative to a similar-sized control group. ${ }^{77}$ However, further research is needed to better understand how chronic physical activity participation may influence inhibitory control processes in children with ADHD.

More research is needed to understand the specific components of exercise that optimize the affect of exercise on cognition and how other factors (eg, age, personality, nutrition) may relate to changes in cognition associated with acute exercise. Furthermore, given that our ADHD group represents a subpopulation of children with less severe symptoms of ADHD, the extent to which the effects that we observed generalize to children with more severe cases of ADHD, those with comorbid conditions, or those undergoing pharmacologic treatment remains unknown. Thus, future research will need to investigate these factors further to better understand the utility of acute exercise in enhancing inhibition in these populations and how acute bouts of exercise may combine and compare with other more traditional ADHD treatment strategies. However, given that approximately $44 \%$ of US children with ADHD do not receive pharmacologic pharmacologic treatment, ${ }^{78}$ these findings may have clinical utility in enhancing cognitive function in children with ADHD.

It is also important to note that we do not yet have a clear understanding regarding the half-life of a single bout of exercise, given that the limited research in this area has investigated multiple time points following an acute bout of physical activity to examine the persistence of exerciseinduced modulations. Within the small body of existent research, conflicting findings have emerged, with some findings suggesting that acute exercise may only exhibit a short duration of influence over aspects of cognitive processing speed, ${ }^{79}$ and others reporting exercise-induced enhancements in inhibition and working memory persisting for at least 60 minutes after cessation of exercise. ${ }^{28,80}$ Clearly, a much-needed area of future research is on better characterizing the duration of the potential benefits for cognition incurred by an acute bout of physical activity, which is likely complicated by the mode, intensity, and duration of the exercise bout, as well as 
individual differences and the sensitivity of the measure of cognitive function used.

Given that previous research has found that children with ADHD are less likely to participate in vigorous physical activity and organized sports compared with children without ADHD, ${ }^{81}$ our findings suggest that motivating children with ADHD to be physically active may have positive affects on aspects of neurocognitive function and inhibitory control. These findings, which demonstrate positive effects in both children with ADHD and children without ADHD, provide additional support for recommendations by the National Association for Sport and Physical Education to incorporate short bouts of exercise during the school day as part of a comprehensive school-based physical activity program. ${ }^{82}$

Submitted for publication May 10, 2012; last revision received Aug 6, 2012; accepted Aug 24, 2012.

Reprint requests: Matthew B. Pontifex, PhD, Michigan State University, Department of Kinesiology, 27P IM Sports Circle, East Lansing, MI 488241049. E-mail: pontifex@msu.edu

\section{References}

1. American Psychiatric Association. Diagnostic and statistical manual of mental disorders. 4th ed. Washington, DC: American Psychiatric Association; 2000.

2. Biederman J. Attention-deficit/hyperactivity disorder: a life-span perspective. J Clin Psychiatry 1998;59:4-16.

3. Wolraich ML, Hannah JN, Baumgaertel A, Feurer ID. Examination of DSM-IV criteria for attention deficit hyperactivity disorder in a county-wide sample. J Dev Behav Pediatr 1998;19:162-8.

4. Banaschewski T, Ruppert S, Tannock R, Albrecht B, Becker A, Uebel H, et al. Colour perception in ADHD. J Child Psychol Psychiatry 2006;47: $568-72$.

5. Schachar R, Mota VL, Logan GD, Tannock R, Klim P. Confirmation of an inhibitory control deficit in attention-deficit/hyperactivity disorder. J Abnorm Child Psychol 2000;28:227-35.

6. Barkley RA. Behavioral inhibition, sustained attention, and executive functions. Psychol Bull 1997;121:65-94.

7. Albrecht B, Brandeis D, Uebel H, Heinrich H, Mueller UC, Hasselhorn $\mathrm{M}$, et al. Action monitoring in boys with attentiondeficit/hyperactivity disorder, their nonaffected siblings, and normal control subjects: evidence for an endophenotype. Biol Psychiatry 2008;64:615-25.

8. Barry RJ, Johnstone SJ, Clarke AR. A review of electrophysiology in attention-deficit/hyperactivity disorder, II: ERPs. Clin Neuropsychol 2003;114:184-98.

9. Jonkman LM, Kemner C, Verbaten MN, Van Engeland H, Kenemans JL, Camfferman G, et al. Perceptual and response interference in children with attention-deficit hyperactivity disorder, and the effects of methylphenidate. Psychophysiology 1999;36:419-29.

10. Jonkman LM, Kemner C, Verbaten MN, Van Engeland $H$, Camfferman G, Buitelaar JK, et al. Attentional capacity, a probe ERP study: differences between children with attentional-deficit hyperactivity disorder and normal control children and effects of methylphenidate. Psychophysiology 2000;37:334-46.

11. Kemner C, Verbaten MN, Koelega HS, Buitelaar JK, van der Gaag R, Camfferman G, et al. Event-related brain potentials in children with attention-deficit and hyperactivity disorder: effects of stimulus deviancy and task relevance in the visual and auditory modality. Biol Psychiatry 1996;40:522-34.

12. Liotti M, Pliszka SR, Perez R, Kothmann D, Woldorff MG. Abnormal brain activity related to performance monitoring and error detection in children with ADHD. Cortex 2005;41:377-88.
13. Liotti M, Pliszka SR, Perez R, Luus B, Glahn D, Semrud-Clikeman M. Electrophysiological correlates of response inhibition in children and adolescents with ADHD: influence of gender, age, and previous treatment history. Psychophysiology 2007;44:936-48.

14. Loiselle DL, Stamm JS, Maitinsky S, Whipple SC. Evoked potential and behavioral signs of attentive dysfunctions in hyperactive boys. Psychophysiology 1980;17:193-201.

15. van Meel CS, Heslenfeld DJ, Oosterlan J, Sergeant JA. Adaptive control deficits in attention-deficit/hyperactivity disorder (ADHD): the role of error processing. Psychiatry Res 2007;151:211-20.

16. Wiersema R, van der Meere J, Roeyers H, Coster RV, Baeyens D. Event rate and ERPs in ADHD. J Child Psychol Psychiatry 2006;47:560-7.

17. Solanto MV, Arnsten AT, Castellanos FX. Stimulant drugs and ADHD: basic and clinical neuroscience. New York: Oxford University Press; 2001.

18. Wilson LJ, Jennings JN. Parents' acceptability of alternative treatments for attention-deficit hyperactivity disorder. J Atten Disord 1996;1:114-21.

19. American Academy of Pediatrics. ADHD: clinical practice guideline for the diagnosis, evaluation, and treatment of attention-deficit/ hyperactivity disorder in children and adolescents. Pediatrics 2011;128: 1007-22.

20. Gapin JI, Labban JD, Etnier JL. The effects of physical activity on attention deficit hyperactivity disorder symptoms: the evidence. Prev Med 2011;52:S70-4.

21. Panksepp J. Can PLAY diminish ADHD and facilitate the construction of the social brain. J Am Acad Child Adolesc Psychiatry 2007;16:57-66.

22. Tantillo M, Kesick CM, Hynd GW, Dishman RK. The effects of exercise on children with attention-deficit hyperactivity disorder. Med Sci Sports Exer 2002;34:203-12.

23. Medina JA, Netto TLB, Muszkat M, Medina AC, Botter D, Orbetelli R, et al. Exercise impact on sustained attention of ADHD children, methylphenidate effects. ADHD Atten Deficit Hyper Dis 2010;2:49-58.

24. Caterino MC, Polack ED. Effects of two types of activity on the performance of second-, third-, and fourth-grade students on a test of concentration. Percept Mot Skills 1999;89:245-8.

25. Mahar MT, Murphy SK, Rowe DA, Golden J, Shields AT, Raedeke TD. Effects of a classroom-based program on physical activity and on-task behavior. Med Sci Sports Exer 2006;38:2086-94.

26. McNaughten D, Gabbard C. Physical exertion and the immediate mental performance of sixth-grade children. Percept Mot Skills 1993;77: 1155-9.

27. Gabbard C, Barton J. Effects of physical activity on mathematical computation among young children. J Psychol 1979;103:287-8.

28. Hillman CH, Pontifex MB, Raine LB, Castelli DM, Hall EE, Kramer AF. The effect of acute treadmill walking on cognitive control and academic achievement in preadolescent children. Neurosci 2009;159:1044-54.

29. Hillman $\mathrm{CH}$, Pontifex MB, Themanson JR. Acute aerobic exercise effects on event-related brain potentials. Exerc Cognit Funct 2009;8: 161-78.

30. Kamijo K, Nishihira Y, Hatta A, Kaneda T, Wasaka T, Kida T, et al. Differential influences of exercise intensity on information processing in the central nervous system. Eur J Appl Physiol 2004;92:305-11.

31. Kamijo K, Nishihira Y, Higashiura T, Kuroiwa K. The interactive effect of exercise intensity and task difficulty on human cognitive processing. Int J Psychophys 2007;65:114-21.

32. Kamijo K, Hayashi Y, Sakai T, Yahiro T, Tanaka K, Nishihira Y. Acute effects of aerobic exercise on cognitive function in older adults. J Gerontol B Psychol Sci 2009;64:356-63.

33. Bussing R, Zima BT, Gary FA, Garvan CW. Barriers to detection, helpseeking, and service use for children with ADHD symptoms. J Behav Health Serv Res 2003;30:176-89.

34. DuPaul GT, Power TJ, Anastopoulos AD, Reid R. ADHD rating scale, IV: Checklists, norms, and clinical interpretation. New York: Guilford Press; 1998.

35. Rutter M, Bailey A, Lord C. The social communication questionnaire manual. Los Angeles: Western Psychological Services; 2003.

36. Achenbach TM, Rescorla LA. Manual for the ASEBA school-age forms and profiles. Burlington, VT: University of Vermont, Research Center for Children, Youth, and Families; 2001. 
37. Eriksen CW, Eriksen BA. Effects of noise letters upon the identification of a target letter in a non-search task. Percept Psychophys 1974;25:249-63.

38. Pontifex MB, Raine LB, Johnson CR, Chaddock L, Voss MW, Cohen NJ, et al. Cardiorespiratory fitness and the flexible modulation of cognitive control in preadolescent children. J Cogn Neurosci 2011; 23:1332-45.

39. Epstein JN, Brinkman WB, Froehlich T, Langberg JM, Narad ME, Antonini TN, et al. Effects of stimulant medication, incentives, and event rate on reaction time variability in children with ADHD. Neuropsychopharm 2011;36:1060-72.

40. Johnson KA, Kelly SP, Bellgrove MA, Barry E, Cox M, Gill M, et al. Response variability in attention deficit hyperactivity disorder: evidence for neuropsychological heterogeneity. Neuropsycholog 2007;45: 630-8.

41. Mezzacappa E. Alerting, orienting, and executive attention: developmental properties and sociodemographic correlates in an epidemiological sample of young, urban children. Child Dev 2004;75: 1373-86.

42. Gehring WJ, Goss B, Coles MGH, Meyer DE, Donchin E. A neural system for error detection and compensation. Psych Sci 1993;4:385-90.

43. Kerns JG, Cohen JD, MacDonald AWI, Cho RY, Stenger VA, Carter CS. Anterior cingulate conflict monitoring and adjustments in control. Science 2004;303:1023-6.

44. Mathewson KJ, Dywan J, Segalowitz SJ. Brain bases of error-related ERPs as influenced by age and task. Biol Psychol 2005;70:88-104.

45. Coles MGH, Gratton G, Fabiani M. ERPs. In: Cacioppo JT, Tassinary LG, eds. Principles of psychophysiology: physical, social, and inferential elements. New York: Cambridge University Press; 1990. p. 413-55.

46. Polich J. Updating P300: an integrative theory of P3a and P3b. Clin Neurophysiol 2007;118:2128-48.

47. Ilan AB, Polich J. P300 and resposne time from a manual Stroop task. Clin Neurophysiol 1999;110:367-73.

48. Gehring WJ, Knight RT. Prefrontal-cingulate interactions in action monitoring. Nat Neurosci 2000;3:516-20.

49. Wilkinson GS. Wide Range Achievement Test 3: administration manual. Wilmington, DE: Jastak Associates; 1993.

50. Kaufman AS, Kaufman NL. Kaufman Brief Intelligence Test manual. Circle Pines, MN: American Guidance Service; 1990.

51. Thomas S, Reading J, Shephard RJ. Revision of the Physical Activity Readiness Questionnaire (PAR-Q). Canadian J Sport Sci 1992;17:338-45.

52. Taylor SC, Whincup PH, Hindmarsh PC, Lampe F, Odoki K, Coock DG. Performance of a new pubertal self-assessment questinnaire: a preliminary study. Paediatr Perinat Epidemiol 2001;15:88-94.

53. Erford BT. Disruptive Behavior Rating Scale parent/treacher manual. East Aurora, NY: Slosson Educational Publications; 1993.

54. Carter CS, Braver TS, Barch DM, Botvinick MM, Noll D, Cohen JD. Anterior cingulated cortex, error detection, and the online monitoring of performance. Science 1998;280:747-9.

55. Dehaene S, Posner MI, Tucker DM. Localization of a neural system for error detection and compensation. Psychol Sci 1994;5:303-5.

56. Miltner WR, Lemke U, Weiss T, Holroyd C, Scheffers MK, Coles MGH. Implementation of error-processing in the human anterior cingulated cortex: a source analysis of the magnetic equivalent of the errorrelated negativity. Biol Psychol 2003;64:157-66.

57. Pontifex MB, Scudder MR, Brown M, O'Leary KC, Wu C, Themanson JR, et al. On the number of trials necessary for stabilization of error-related brain activity across the lifespan. Psychophysiology 2010;47:767-73

58. Bull R, Scerif G. Executive functioning as a predictor of children's mathematics ability: inhibition, switching, and working memory. Dev Neuropsychol 2001;19:273-93.

59. St Clair-Thompson HL, Gathercole SE. Executive functions and achievements in school: shifting, updating, inhibition, and working memory. Q J Exp Psychol (Hove) 2006;59:745-59.

60. Satterfield JH, Cantwell DP. Proceedings: CNS function and response to methylphenidate in hyperactive children. Psychopharm Bull 1974; 10:36-8.
61. Barry RJ, Clarke AR, Johnstone SJ, McCarthy R, Selikowitz M. Electroencephalogram theta/beta ratio and arousal in attention-deficit/ hyperactivity disorder: evidence of independent processes. Biol Psychiatry 2009;66:398-401.

62. Bracken BA, Boatwright BS. Clinical assessment of attention deficitchild/adult professional manual. Lutz, FL: Psychological Assessment Resources; 2005.

63. Chaddock L, Erickson KI, Prakash RS, VanPatter M, Voss MW, Pontifex MB, et al. Basal ganglia volume is associated with aerobic fitness in preadolescent children. Dev Neurol 2010;32:249-56.

64. Chaddock L, Erickson KI, Prakash RS, Kim JS, Voss MW, VanPatter M, et al. A neuroimaging investigation of the association between aerobic fitness, hippocampal volume, and memory performance in preadolescent children. Brain Res 2010;1358:172-83.

65. Chaddock L, Erickson KI, Prakash RS, Voss MW, VanPatter M, Pontifex MB, et al. A functional MRI investigation of the association between childhood aerobic fitness and neurocognitive control. Biol Psychol 2012;89:260-8.

66. Hillman CH, Buck SM, Themanson JR, Pontifex MB, Castelli DM. Aerobic fitness and cognitive development: event-related brain potential and task performance indices of executive control in preadolescent children. Dev Psychol 2009;45:114-29.

67. Aylward EH, Reiss AL, Reader MJ, Singer HS, Brown JE, Denckla MB. Basal ganglia volumes in children with attention-deficit hyperactivity disorder. J Child Neurol 1996;11:112-5.

68. Castellanos FX, Giedd JN, Marsh WL, Hamburger SD, Vaituzis AC, Dickstein DP, et al. Quantitative brain magnetic resonance imaging in attention-deficit/hyperactivity disorder. Arch Gen Psychiatry 1996;53: 607-16.

69. Castellanos FX, Giedd JN, Berquin PC, Walter JM, Sharp W, Tran T, et al. Quantitative brain magnetic resonance imaging in girls with attentiondeficit/hyperactivity disorder. Arch Gen Psychiatry 2001;58:289-95.

70. Dimoska A, Johnstone SJ, Barry RJ, Clarke AR. Inhibitory motor control in children with attention-deficit/hyperactivity disorder: ERPs in the stop-signal paradigm. Biol Psychiatry 2003;54:1345-54.

71. Giedd JN, Castellanos FX, Casey BJ, Kozuch P, King AC, Hamberger SD, et al. Quantitative morphology of the corpus callosum in attention deficit hyperactivity disorder. Am J Psychiatry 1994;151:665-9.

72. Hynd GW, Semrud-Clikeman M, Lorys AR, Novey ES, Eliopulos D, Lyytinen H. Corpus callosum morphology in attention deficithyperactivity disorder: morphometric analysis of MRI. J Learn Disabil 1991;24:141-6.

73. Johnstone SJ, Barry RJ. Auditory ERPs to a two-tone discrimination paradigm in attention deficit hyperactivity disorder. Psychiatry Res 1996;64: 179-92.

74. Pliszka SR, Liotti M, Woldorff MG. Inhibitory control in children with attention-deficit/hyperactivity disorder: ERPs identify the processing component and timing of an impaired right-frontal response-inhibition mechanism. Biol Psychiatry 2000;48:238-46.

75. Rubia K, Overmeyer S, Taylor E, Brammer M, Williams SCR, Simmons A, et al. Hypofrontality in attention deficit hyperactivity disorder during higher-motor control: a study with functional MRI. Am J Psychiatry 1999;156:891-6.

76. Yeo RA, Hill DE, Campbell RA, Vigil J, Petropoulos H, Hart B, et al. Proton magnetic resonance spectroscopy investigation of the right frontal lobe in children with attention-deficit/hyperactivity disorder. J Am Acad Child Adolesc Psychiatry 2003;42:303-10.

77. Verret C, Guay MC, Berthiaume C, Gardiner P, Béliveau L. A physical activity program improves behavior and cognitive functions in children with ADHD: an exploratory study. J Atten Disord 2012;16:71-80.

78. Biederman J, Faraone SV. Attention-deficit hyperactivity disorder. Lancet 2005;366:237-48

79. Barella LA, Etnier JL, Chang YK. The immediate and delayed effects of an acute bout of exercise on cognitive performance in healthy older adults. J Aging Phys Activity 2010;18:87-98.

80. Pontifex MB, Hillman CH, Fernhall B, Thompson KM, Valentini TA. The effect of acute aerobic and resistance exercise on working memory. Med Sci Sport Exer 2009;41:927-34. 
81. Kim J, Mutyala B, Agiovlasitis S, Fernhall B. Health behaviors and obesity among US children with attention deficit hyperactivity disorder by gender and medication use. Prev Med 2011;52:218-22.

82. National Association for Sport and Physical Education. Comprehensive school physical activity programs (position statement). Re- ston, VA: National Association for Sport and Physical Education; 2008.

83. Jenson PS, Martin D, Cantwell DP. Comorbidity in ADHD: implications for research, practice, and DSM-V. J Am Acad Child Adolesc Psychiatry 1997;36:1065-79.

50 Years Ago in The Journal of PEDIATRICs

\section{Clinical and Serologic Observations in Patients with Juvenile Rheumatoid Arthritis and Their Relatives}

Toumbis A, Franklin EC, McEwen C, Kuttner AG. J Pediatr 1963;62:463-73

Toumbis et al described the clinical and serologic features of 50 children with juvenile rheumatoid arthritis (JRA).

1 In 1963 pediatric rheumatology did not exist as a subspecialty, and there were very few physicians (mainly in England) who specialized in treating children with arthritis. Most children were treated by adult rheumatologists or pediatricians, such as the authors. The study was therefore performed prior to the first classification of JRA subtypes by the American Rheumatism Section of the Arthritis Foundation in the 1970s. Thus, the authors lumped all of their patients into one group. Their conclusion was that JRA is very similar to adult rheumatoid arthritis with certain clinical features modified by age. The method of measuring rheumatoid factor was different than that currently used, using sheep erythrocyte agglutination and latex tests.

This study is an example of how medical research often undergoes circular changes, and discounted theories are shown much later to be, at least partially, correct. The evolution of the classification of childhood arthritis has undergone many changes with one of the primary objectives to differentiate chronic childhood arthritis from adult arthritis. This included the change in nomenclature from JRA to juvenile idiopathic arthritis and the expansion of the subtypes of childhood arthritis. However, recent translational research has showed a large degree of commonality between most types of chronic childhood arthritis and adult arthritis except for arthritis that starts at a young age (usually between 1-4 years), mainly in girls, with a positive antinuclear antibody and a high risk of chronic anterior uveitis. This type of arthritis appears to be unique to children. These findings may lead soon to a new reclassification of childhood arthritis, perhaps with new names reflecting the similarity of many types of arthritis in children and adults. ${ }^{1}$ Thus, the clinical observations of Toumbis et al, without the supportive basic and translational research since pediatric rheumatology became a subspecialty, may have been ahead of its time.

\section{Reference}

Philip J. Hashkes, MD, MSc Pediatric Rheumatology Unit Shaare Zedek Medical Center Jerusalem, Israel http://dx.doi.org/10.1016/j.jpeds.2012.10.033

1. Martini A. It is time to rethink juvenile idiopathic arthritis classification and nomenclature. Ann Rheum Dis 2012;71:1437-9. 